\title{
Serum 25-hydroxyvitamin D might be negatively associated with hyperuricemia in U.S. adults: an analysis of the National Health and Nutrition Examination Survey 2007-2014
}

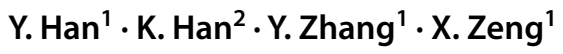 \\ Received: 2 March 2021 / Accepted: 11 July 2021 / Published online: 26 August 2021 \\ (c) The Author(s) 2021
}

\begin{abstract}
Purpose The results of previous studies on the relationship between serum 25-hydroxyvitamin D [25(OH)D] and hyperuricemia are controversial. We hypothesized that serum 25(OH)D concentrations of U.S. adults would negatively correlate with the risk of hyperuricemia.

Method Data came from the National Health and Nutrition Examination Survey 2007-2014 were used, after excluding those who met at least one of the exclusion criteria, a total of 9096 male individuals and 9500 female individuals aged 18 years or older were included. Binary logistic regression analysis and restricted cubic spline with fully adjusted confounding factors were applied to evaluate the association between serum $25(\mathrm{OH}) \mathrm{D}$ and hyperuricemia. We further performed stratified analysis and sensitivity analysis to minimize the influence of gender, metabolic syndrome, obesity and renal dysfunction on the above association.

Results We found a negative correlation between serum 25(OH)D and hyperuricemia. In the binary logistic regression analysis, compared with the highest serum $25(\mathrm{OH}) \mathrm{D}$ quartile $[\mathrm{Q} 4: 25(\mathrm{OH}) \mathrm{D}>77.10 \mathrm{nmol} / \mathrm{L}]$ group, the odds ratios $(95 \%$ confidence intervals) in the lowest quartile [Q1: $25(\mathrm{OH}) \mathrm{D} \leq 43.20 \mathrm{nmol} / \mathrm{L}]$ was $1.46(1.22-1.75)$ in the fully adjusted model. Restricted cubic spline analysis showed L-shaped and non-linear relationships between 25(OH)D and hyperuricemia. In sensitivity analysis, after restricting to participants without significant renal dysfunction and obesity, the above association remained significant. After restricting to participants who were diagnosed as metabolic syndrome, above association remained significant in the fully adjusted model. In stratified analysis by gender, the association remained significant among males and females.
\end{abstract}

Conclusions Serum 25(OH)D might be inversely associated with hyperuricemia in general U.S. adults. From our study, for people with unexplained hyperuricemia, screening for serum Vitamin D concentration might be necessary.

Keywords Uric acid $\cdot 25$-hydroxyvitamin D $\cdot$ Vitamin D $\cdot$ Hyperuricemia $\cdot$ NHANES

Y. Han and K. Han are Co-first authors.

Y. Zhang

zhangyun10806@pumch.cn

$\triangle$ X. Zeng

zxjpumch@126.com

1 Department of General Internal Medicine, Peking Union Medical College Hospital, Chinese Academy of Medical Sciences, No. 1 Shuaifuyuan, Dongcheng District, Beijing 100730, China

2 Department of Critical Care Medicine, The Affiliated Yantai Yuhuangding Hospital of Qingdao University, Yantai 264000, Shandong, China

\begin{tabular}{ll}
\multicolumn{2}{l}{ Abbreviations } \\
NHANES & $\begin{array}{l}\text { National Health and Nutrition Examination } \\
\text { Surveys }\end{array}$ \\
CKD & Chronic kidney disease \\
SUA & Serum uric acid \\
25(OH)D & 25-Hydroxyvitamin D \\
BMI & Body mass index \\
ORs & Odds ratios \\
CIs & Confidence intervals \\
eGFR & Estimation of the glomerular filtration rate \\
PIR & Poverty income ratio \\
LC-MS & Liquid chromatography-tandem mass \\
& spectrometric \\
PTH & Parathyroid hormone
\end{tabular}




\section{Introduction}

Vitamin D from both endogenous synthesis by skin and exogenous intake from diet are metabolized in the liver to 25-hydroxyvitamin $\mathrm{D}[25(\mathrm{OH}) \mathrm{D}]$, which is the most widely used marker and estimator of Vitamin D status. An epidemiological investigation in National Health and Nutrition Examination Survey (NHANES) has shown the overall shift of the population toward lower serum $25(\mathrm{OH}) \mathrm{D}$ concentrations and higher prevalence of hypovitaminosis D [1]. Previous study has found that $18.3 \%$ of US noninstitutionalized population were at a risk of Vitamin D inadequacy and 5\% were at a risk of deficiency [2]. Vitamin D plays an important role in regulating the normal homeostasis of calcium and phosphorus. Adequate concentrations of Vitamin D are necessary for bone health, while low concentrations of Vitamin D are associated with rickets and osteomalacia [2]. In addition, Vitamin D has many non-calcemic biological functions. Experimental studies indicate that Vitamin D, as a negative regulator of renin-angiotensin system, can suppress renin expression [3]. Furthermore, Vitamin D maintains pancreatic $\beta$ cells' function through binding of vitamin $\mathrm{D}$ with vitamin $\mathrm{D}$ receptor, transduction of insulin signaling and engaging in regulation of $\mathrm{Ca}^{2+}$ flux in the pancreatic $\beta$ cells [4]. Vitamin D is also associated with cell proliferation and differentiation and can inhibit the growth of cancers in experimental animals [5]. Observational studies have revealed the association between Vitamin D deficiency and a variety of clinical conditions, such as poor blood pressure control, risk of hypertension [6, 7], cardiovascular morbidity and mortality [8], higher fasting and postprandial blood glucose in type 2 diabetes mellitus patients [9], dyslipidemia [10] and autoimmune disease [11]. Even if the evaluation of the circulating levels of $25(\mathrm{OH}) \mathrm{D}$ in these categories of subjects per se does not justify the supplementation of vitamin $\mathrm{D}$ for the therapeutic purpose at the moment, controversial results in this regard have been published and there is no general consensus on these topics [12-15].

Uric acid is the end product of purine nucleotide metabolism and hyperuricemia can occur as a result of overproduction or underexcretion of serum uric acid (SUA), but the pathophysiological mechanism of hyperuricemia has not yet been fully elucidated. SUA has a protective effect in neurodegenerative disease, such as dementia, Parkinson's disease [16]; however, hyperuricemia is a common health problem which affects nearly $21 \%$ of US adults [17]. In addition to joint involvement, hyperuricemia has been linked with different degrees of some metabolic disorders [18-21], including hypertension, obesity, type 2 diabetes and metabolic syndrome. Numerous epidemiological studies have shown that increased SUA is an independent risk factor for cardiovascular and all-cause mortality [22, 23].
Previous studies have demonstrated the association between SUA and Vitamin D, but the results are inconsistent and controversial. Some studies have pointed out that $25(\mathrm{OH}) \mathrm{D}$ insufficiency is significantly associated with increased odds ratios (ORs) of elevated SUA [24, 25], which is consistent with our results. However, other studies have come to different conclusions [26, 27]. We hypothesized that serum $25(\mathrm{OH}) \mathrm{D}$ concentrations of U.S. adults would negatively correlate with the risk of hyperuricemia. Binary logistic regression analysis and restricted cubic spline with fully adjusted confounding factors were applied to evaluate the association between serum $25(\mathrm{OH}) \mathrm{D}$ concentrations and hyperuricemia. Therefore, we performed this study in a large, nationally representative cohort of U.S. adults using data from the NHANES 2007-2014 to explore whether there was a negative correlation between vitamin $\mathrm{D}$ and hyperuricemia and hoped it can provide some information for the treatment of hyperuricemia.

\section{Materials and methods}

\section{Data source and study population}

The NHANES, which was conducted by the Centers for Disease Control and Prevention of America, collected information regarding the health and nutritional status of the U.S. population every 2 years. NHANES used a complex, stratified sampling design, which can select representative samples of non-institutionalized civilians. Participants underwent a detailed in-home interview and a physical examination and blood specimen collection at specially equipped mobile examination centers [28]. The study was conducted in accordance with the Declaration of Helsinki [29]. Written informed consent was obtained from all participants prior to completing the NHANES, and all data were de-identified by the National Center for Health Statistics before being made publicly available.

Participants for the present analysis consisted of individuals enrolled in four 2-year cycle surveys conducted in 2007-2008, 2009-2010, 2011-2012 and 2013-2014. A total of 40,617 adult participants enrolled in the NHANES from 2007 to 2014, and the exclusion criteria were to meet one of the following: (1) age $<18$ years $(n=15,885)$; (2) participants whose serum uric acid data $(n=2,430)$ and serum 25(OH)D data $(n=747)$ were missing; (3) self-reported cancer or malignancy $(n=1914)$; (4) being pregnant or breastfeeding $(n=328)$; (5) self-reported gout or received urate-lowering therapy $(n=717)$. Eventually, a large national representative sample (9096 males, 9500 females) among the general adult US population was included in this study. The flow chart of the screening process is shown in Fig. 1. 


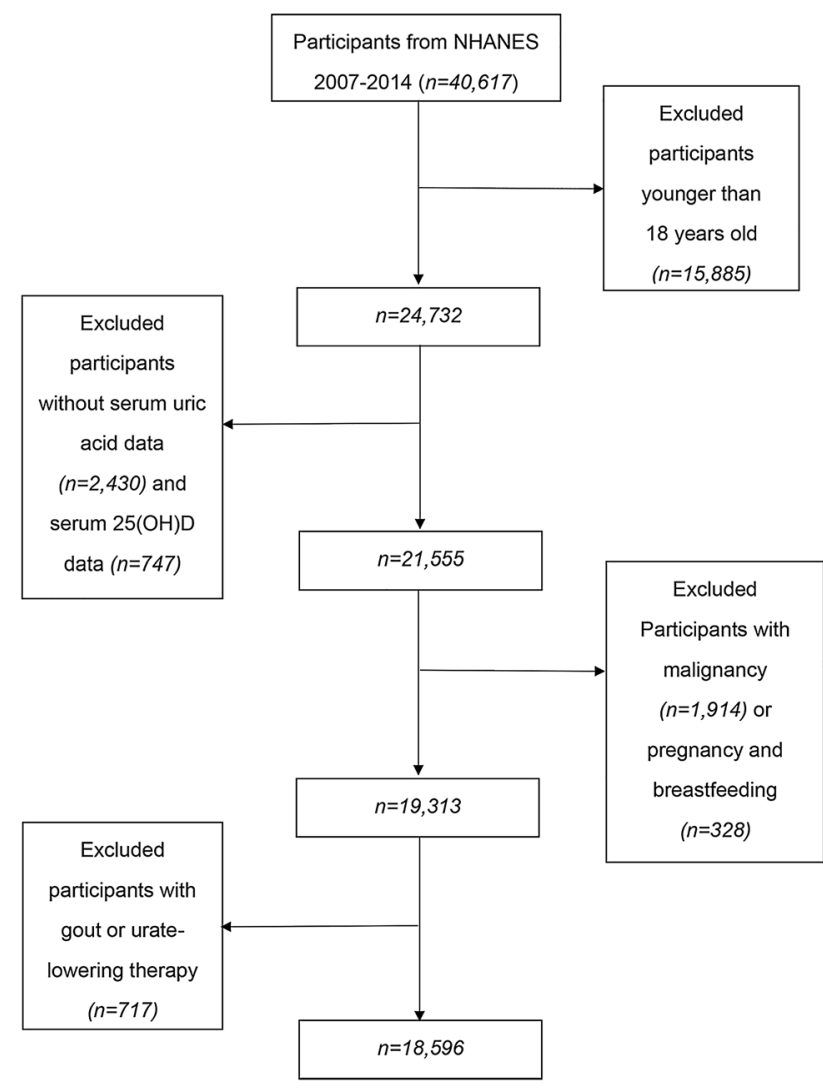

Fig. 1 Flow chart of the screening process for the selection of eligible participants

\section{Study variables}

Serum 25(OH)D was used as a direct measure of Vitamin D status, which reflected cumulative endogenous synthesis and exogenous supplement. Serum 25-hydroxyvitamin D3 and 25-hydroxyvitamin D2 are measured by an ultra-high performance liquid chromatography-tandem mass spectrometric method [30]. The ultra-high performance liquid chromatography-tandem mass spectrometric (LC-MS) method has improved sensitivity and specificity for serum $25(\mathrm{OH}) \mathrm{D}$ metabolites, and the standardization of serum $25(\mathrm{OH}) \mathrm{D}$ data allows for comparison across different survey cycles of the NHANES, providing sufficient power to study risk associated with varying concentrations of serum 25(OH)D [31]. In addition, the preparation of reagents and quality control materials for the LC-MS method are standardized; previous study found no significant differences between the 2-year survey cycles [32]. Total 25(OH) $\mathrm{D}$ is the sum of 25-hydroxyvitamin D2 and 25-hydroxyvitamin D3. Serum uric acid is measured by DxC800 synchron using a timed endpoint method [33]. Hyperuricemia is defined as serum uric acid level $\geq 420 \mu \mathrm{mol} / \mathrm{L}$ ( $7 \mathrm{mg} /$ $\mathrm{dL})$ and $\geq 360 \mu \mathrm{mol} / \mathrm{L}(6 \mathrm{mg} / \mathrm{dL})$ in males and females, respectively [34].
Potential confounding factors in this study include age, gender, race (Mexican American, Other Hispanic, NonHispanic White, Non-Hispanic Black and Other race), body mass index (BMI) (Normal: between 18.5 and $25 \mathrm{~kg} / \mathrm{m}^{2}$; overweight: between 25 and $30 \mathrm{~kg} / \mathrm{m}^{2}$; obesity: $\geq 30 \mathrm{~kg} / \mathrm{m}^{2}$ ) [35], waist circumference, estimation of the glomerular filtration rate [eGFR is calculated according to the Modification of Diet in Renal Disease equation, eGFR $=175 \times$ standardized $\mathrm{Scr}^{-1.154} \times \mathrm{age}^{-0.203} \times 1.212$ (if black) $\times 0.742$ (if female)] [36], and significant chronic kidney dysfunction is defined as decreased eGFR less than $60 \mathrm{~mL} / \mathrm{min} / 1.73 \mathrm{~m}^{2}$ [37]. Poverty income ratio (PIR) was used to define income, which was categorized as less than 0.99 and 1 or more. A PIR lower than 1.0 represents a person is living under poverty line. Serum calcium, phosphorus, total cholesterol, triglyceride, smoking status (smoked at least 100 cigarettes in life or not) and drinking status (had at least 12 alcohol drinks/1 year) were also involved in this study. The history of hypertension, diabetes was defined as participants selfreported diagnosis of hypertension or diabetes by physicians. Degree of physical activity (Physically active group, insufficiently active group and inactive group) was also involved in this study.

\section{Statistical analysis}

All statistical analyses were conducted with $\mathrm{R}$ 4.0.2. To account for the complex sampling design and ensure nationally representative estimates, all analyses were adjusted for survey design and weighting variables. New sample weight (the original 2-year sample weight divided by 4) was constructed according to the analytical guidelines of the NHANES [38]. The normality of continuous variables was tested with Kolmogorov-Smirnov normality test. Normally distributed variables were described with mean \pm standard deviation, and non-normally distributed continuous variables were described with median (interquartile range). The median values among different serum 25(OH)D and SUA groups were compared with the Mann-Whitney $U$ test and Kruskal-Wallis test. The $\chi^{2}$ test was adopted to compare the percentages of categorical variables among different serum 25(OH)D and SUA groups. The Bonferroni test was used for the intergroup comparison. Serum $25(\mathrm{OH}) \mathrm{D}$ level in binary logistic regression analyses were modeled in quartiles: Q1 $(25(\mathrm{OH}) \mathrm{D} \leq 43.20 \mathrm{nmol} / \mathrm{L})$, Q2 $(43.20<25(\mathrm{OH}) \mathrm{D} \leq 59.70 \mathrm{nmol} / \mathrm{L}), \mathrm{Q} 3(59.70<25(\mathrm{OH})$ $\mathrm{D} \leq 77.10 \mathrm{nmol} / \mathrm{L})$ and $\mathrm{Q} 4(25(\mathrm{OH}) \mathrm{D}>77.10 \mathrm{nmol} / \mathrm{L})$, with the fourth quartile $(\mathrm{Q} 4)$ as the reference group. Binary logistic regression analysis was conducted to examine the association between 25(OH)D and SUA. Age and gender were adjusted in model 1 , and model 2 was additionally adjusted for race, BMI, waist circumference, PIR, drinking status, smoking status, physical activity, hypertension, diabetes, 
total cholesterol, triglyceride, eGFR, serum calcium and phosphorus. Restricted cubic spline analysis with 3 knots of the vitamin $\mathrm{D}$ concentration was used to characterize the dose-response relationship in the logistic regression Model 2. To exclude the influence of renal dysfunction and obesity, we then performed a sensitivity analysis by restricting to participants without chronic kidney disease and obesity participants. In addition, gender stratified analysis was performed to examine above association. We also performed above analysis in participants who were diagnosed as metabolic syndrome. Participants who with at least three of the five components (hypertension, diabetes, abdominal obesity, hypertriglyceridemia, or low levels of HDL) were diagnosed as metabolic syndrome [39]. In our study, quartiles of serum vitamin D were used to explore the relationship between vitamin D and SUA, and we used restricted cubic splines to characterize the dose-response relationship between vitamin $\mathrm{D}$ and hyperuricemia for the first time. A two-sided $P<0.05$ was considered statistically significant.

\section{Results}

A total of 18,596 individuals (9096 men, 9500 women) were involved in our study. All participants were categorized into five racial groups: Mexican American $(n=3067)$, Other Hispanic $(n=2026)$, Non-Hispanic White $(n=7642)$, NonHispanic Black $(n=3850)$, Other race $(n=2011)$. The mean age was $46.02 \pm 17.95$ years, the mean serum $25(\mathrm{OH}) \mathrm{D}$ level was $62.17 \pm 26.50 \mathrm{nmol} / \mathrm{L}$ and mean SUA level was $321.75 \pm 83.19 \mu \mathrm{mol} / \mathrm{L} .17 .10 \%$ of the participants met the diagnostic criteria of hyperuricemia and $12.21 \%$ of the participants had a SUA concentration $\geq 420 \mu \mathrm{mol} / \mathrm{L}$. The clinical characteristics of participants with different serum Vitamin D levels are shown in Table 1. We found a greater proportion of hyperuricemia participants that belonged to the lowest quartile of Vitamin D level. The two lower 25(OH)D quartiles showed larger waist circumference than the two higher quartiles. With the increase in $25(\mathrm{OH}) \mathrm{D}$ quartiles, the proportion of physically active participants increased gradually, while the median of BMI, eGFR and the proportion of people living under poverty line declined gradually. The trend of eGFR in our research was consistent with the study conducted by Seong-Woo Choi, and the reduced $25(\mathrm{OH}) \mathrm{D}$ clearance in participants with lower eGFR might be the possible mechanism $[40,41]$.

The clinical characteristics of participants with different SUA levels are shown in Table 2. People with hyperuricemia were older (52 vs. 44 years old) and have higher serum calcium ( 2.38 vs. $2.35 \mathrm{mmol} / \mathrm{L}$ ), triglyceride (1.67 vs. $1.25 \mathrm{mmol} / \mathrm{L})$, higher BMI (30.94 vs. $\left.27.02 \mathrm{~kg} / \mathrm{m}^{2}\right)$ and waist circumference ( $105.6 \mathrm{vs} .94 .4 \mathrm{~cm}$ ), and higher prevalence of hypertension (50.3 vs. $27.1 \%$ ) and diabetes (16.0 vs. 9.4\%).
Participants in normal SUA level group are younger and physically active, more likely to be females and have higher eGFR (93.42 vs. $79.21 \mathrm{~mL} / \mathrm{min} / 1.73 \mathrm{~m}^{2}$ ).

The results of binary logistic regression analysis between serum $25(\mathrm{OH}) \mathrm{D}$ levels and hyperuricemia are presented in Table 3. In Table 3, the crude ORs with $95 \%$ confidence intervals (CIs) of hyperuricemia are 0.95 (0.82-1.09), 1.16 (0.98-1.37) and 1.33 (1.14-1.55) in Q3, Q2 and Q1 versus Q4 of 25(OH)D, respectively. In Model 1, after adjustment for age and gender, the adjusted ORs with $95 \% \mathrm{CI}$ are 0.97 (0.84-1.11), 1.23 (1.04-1.46) and $1.49(1.28-1.73)$ in Q3, Q2 and Q1 versus Q4 of 25(OH)D, respectively. In Model 2 , the multivariate-adjusted ORs with $95 \%$ CIs of hyperuricemia are $0.96(0.81-1.14), 1.14(0.94-1.38)$ and 1.46 $(1.22-1.75)$ in Q3, Q2 and Q1 versus Q4 of serum 25(OH) $\mathrm{D}$, respectively. The results of the restricted cubic spline dose-response relationship analysis between serum $25(\mathrm{OH})$ $\mathrm{D}$ and hyperuricemia were presented in Fig. 2. We found a suggestion of L-shaped associations of serum $25(\mathrm{OH}) \mathrm{D}$ concentration and hyperuricemia. The prevalence of hyperuricemia decreased with increasing serum $25(\mathrm{OH}) \mathrm{D}$ concentration and showed a nonlinear dose-response relationship $(P$ non-linearity $=0.0031)$.

Additionally, we further performed sensitivity analysis by excluding participants with significant renal dysfunction (eGFR lower than $60 \mathrm{~mL} / \mathrm{min} / 1.73 \mathrm{~m}^{2}$ ) and obesity participants (BMI $\left.\geq 30 \mathrm{~kg} / \mathrm{m}^{2}\right) ; 11,006$ participants were involved in the sensitivity analysis, and after fully adjusting the same confounding factors, the associations between serum 25(OH)D and hyperuricemia are still significant (Table 4).

In stratified analyses by gender, the results are shown in Table 5. Serum 25(OH)D levels were negatively associated with the risk of hyperuricemia in both men group and women group, and the adjusted ORs with $95 \%$ CIs were 1.30 (1.03-1.65) and $1.55(1.13-2.12)$ in model 2, respectively.

Finally, we performed logistic regression analysis in participants who were diagnosed with metabolic syndrome and the results are presented in Table 6. Serum 25(OH)D levels are negatively associated with the risk of hyperuricemia in model 2; the adjusted ORs with $95 \%$ CIs was 1.49 (1.16-1.91) in Q1 versus Q4 of serum 25(OH)D.

\section{Discussion}

In this study, we combined data from the NHANES 2007-2014 to investigate the association; a total of 9096 men and 9500 women aged 18 years or older were included. In binary logistic regression analysis, we found that serum $25(\mathrm{OH}) \mathrm{D}$ might be negatively associated with the risk of hyperuricemia. The association between serum $25(\mathrm{OH}) \mathrm{D}$ and hyperuricemia remained significant in both sensitivity analyses and stratified analyses. Restricted cubic spline 
Table 1 Clinical characteristics of the study population in disaggregated by quartiles of serum 25(OH)D level. NHANES 2007-2014 $(N=18,596)$

\begin{tabular}{|c|c|c|c|c|c|}
\hline Serum 25(OH)D quartile & Q1 & Q2 & Q3 & Q4 & $P$ value \\
\hline Number of subjects & 4653 & 4651 & 4644 & 4648 & \\
\hline Age $(\text { year })^{b}$ & $41(27)$ & $43(28)$ & $45(28)$ & $52(30)$ & $<0.01$ \\
\hline Gender $(\%)^{\mathrm{a}}$ & & & & & $<0.01$ \\
\hline Male & $2145(46.1)$ & $2489(53.5)$ & $2493(53.7)$ & $1969(42.4)$ & \\
\hline Female & $2508(53.9)$ & $2162(46.5)$ & $2151(46.3)$ & 2679 (57.6) & \\
\hline $\operatorname{Race}(\%)^{\mathrm{a}}$ & & & & & $<0.01$ \\
\hline Mexican American & $898(19.3)$ & $1047(22.5)$ & $762(16.4)$ & $360(7.7)$ & \\
\hline Other Hispanic & $437(9.4)$ & $664(14.3)$ & $558(12.0)$ & $367(7.9)$ & \\
\hline Non-Hispanic White & $786(16.9)$ & $1504(32.3)$ & $2274(49.0)$ & 3078 (66.2) & \\
\hline Non-Hispanic Black & $1960(42.1)$ & $888(19.1)$ & $571(12.3)$ & $431(9.3)$ & \\
\hline Other race & $572(12.3)$ & $548(11.8)$ & $479(10.3)$ & $412(8.9)$ & \\
\hline Physical activity (\%) ${ }^{\mathrm{a}}$ & & & & & $<0.01$ \\
\hline Inactive & $2734(58.8)$ & $2422(52.1)$ & 2317 (49.9) & 2066 (44.4) & \\
\hline Insufficiently active & $638(13.7)$ & $669(14.4)$ & $705(15.2)$ & $745(16.0)$ & \\
\hline Physically active & $1281(27.5)$ & $1560(33.5)$ & $1622(34.9)$ & $1837(39.5)$ & \\
\hline Waist circumstance $(\mathrm{cm})^{\mathrm{b}}$ & $98.1(23.9)$ & $97.6(20.8)$ & $96.2(20.1)$ & $93.4(21.7)$ & $<0.01$ \\
\hline Body mass index $\left(\mathrm{kg} / \mathrm{m}^{2}\right)^{\mathrm{b}}$ & $29.0(9.9)$ & $28.3(8.0)$ & $27.4(7.3)$ & $26.3(7.1)$ & $<0.01$ \\
\hline Cholesterol $(\mathrm{mmol} / \mathrm{L})^{\mathrm{b}}$ & $4.81(1.45)$ & $4.86(1.42)$ & $4.91(1.40)$ & $4.94(1.45)$ & $<0.01$ \\
\hline Triglyceride $(\mathrm{mmol} / \mathrm{L})^{\mathrm{b}}$ & $1.22(1.13)$ & $1.36(1.26)$ & $1.37(1.23)$ & $1.33(1.14)$ & $<0.01$ \\
\hline $\mathrm{eGFR}\left(\mathrm{mL} / \mathrm{min} / 1.73 \mathrm{~m}^{2}\right)^{\mathrm{b}}$ & $99.5(32.8)$ & $95.4(30.5)$ & $89.7(28.0)$ & $81.6(26.1)$ & $<0.01$ \\
\hline Poverty income ratio $<1(\%)^{\mathrm{a}}$ & $1247(29.4)$ & $1116(26.4)$ & $958(22.4)$ & $786(18.4)$ & $<0.01$ \\
\hline Hyperuricemia $(\%)^{\mathrm{a}}$ & $897(19.3)$ & $798(17.2)$ & $690(14.9)$ & $794(17.1)$ & $<0.01$ \\
\hline Serum $25(\mathrm{OH}) \mathrm{D}(\mathrm{nmol} / \mathrm{L})^{\mathrm{b}}$ & $33.0(11.8)$ & $51.9(8.3)$ & 67.5 (8.5) & $90.8(20.8)$ & $<0.01$ \\
\hline Total calcium $(\mathrm{mmol} / \mathrm{L})^{\mathrm{b}}$ & $2.35(0.125)$ & $2.35(0.100)$ & $2.35(0.100)$ & $2.38(0.100)$ & $<0.01$ \\
\hline Phosphorus $(\mathrm{mmol} / \mathrm{L})^{\mathrm{b}}$ & $1.20(0.226)$ & $1.23(0.226)$ & $1.23(0.226)$ & $1.23(0.258)$ & $<0.01$ \\
\hline Hypertension $(\%)^{\mathrm{a}}$ & $1373(29.5)$ & $1330(28.6)$ & 1377 (29.7) & $1690(35.4)$ & $<0.01$ \\
\hline Diabetes $(\%)^{\mathrm{a}}$ & $507(10.9)$ & $509(11.0)$ & $456(9.8)$ & $489(10.5)$ & 0.26 \\
\hline Had at least 12 alcohol drinks/year $(\%)^{\mathrm{a}}$ & $2740(68.2)$ & $2876(70.2)$ & $3103(74.9)$ & $3119(74.5)$ & $<0.01$ \\
\hline Smoked at least 100 cigarettes in life $(\%)^{\mathrm{a}}$ & $1868(42.5)$ & $1816(41.0)$ & $1999(44.5)$ & $2035(45.2)$ & $<0.01$ \\
\hline
\end{tabular}

Data are number of subjects (percentage) or medians (interquartile ranges)

Serum 25(OH)D quartiles Q1 $(25(\mathrm{OH}) \mathrm{D} \leq 43.20 \mathrm{nmol} / \mathrm{L})$, Q2 $(43.20<25(\mathrm{OH}) \mathrm{D} \leq 59.70 \mathrm{nmol} / \mathrm{L}), \mathrm{Q} 3(59.70<25(\mathrm{OH}) \mathrm{D} \leq 77.10 \mathrm{nmol} / \mathrm{L}), \mathrm{Q} 4$ (25(OH)D $>77.10 \mathrm{nmol} / \mathrm{L})$.

${ }^{\mathrm{a}} \chi^{2}$ test was used to compare the percentage among participants in different groups

${ }^{\mathrm{b}}$ Kruskal-Wallis test was used to compare the median values among participants in different groups

found a non-linear relationship and L-shaped dose-response relationship between serum $25(\mathrm{OH}) \mathrm{D}$ and hyperuricemia.

The mechanisms of the relationship between Vitamin $\mathrm{D}$ and hyperuricemia remain unclear; several possible explanations have been proposed. Primarily, Vitamin D deficiency can cause secondary hyperparathyroidism, which leads to an increase of the serum parathyroid hormone (PTH) concentration [42]. Except for Vitamin $\mathrm{D}$ deficiency, daily calcium intake also affects the level of PTH; reduced intake of calcium is associated with high levels of serum PTH while excessive intake of calcium lowers PTH [43, 44]. Previous studies have shown a positive correlation between PTH and SUA and have suggested that PTH can affect the secretion and transport of uric acid [37, 45, 46], but the detailed mechanism is not clearly explained yet. Additionally, both laboratory studies and observational studies have revealed the association between hypovitaminosis $\mathrm{D}$ and insulin resistance $[4,47,48]$ and vitamin D supplementation has a beneficial effect on insulin sensitivity $[4,49]$, while insulin resistance is inversely correlated to the renal clearance of SUA and can lead to hyperuricemia [18]. Insulin resistance is a major underlying mechanism for the metabolic syndrome, which is often complicated with hyperuricemia. Third, hyperuricemia and obesity are significantly correlated, while low serum Vitamin D is common in obese people 
Table 2 Clinical characteristics of the study population in hyperuricemia group and normal serum uric acid group. NHANES 2007-2014 $(N=18,596)$
Table 3 Weighted odds ratios (95\% confidence intervals) for hyperuricemia of participants across quartiles of serum 25(OH)D, NHANES 2007$2014(N=18,596)$

\begin{tabular}{|c|c|c|c|}
\hline & Normal serum uric acid & Hyperuricemia & $P$ value \\
\hline Number of subjects & 15,417 & 3179 & \\
\hline Age $(\text { year })^{\mathrm{b}}$ & $44(29)$ & $52(31)$ & $<0.01$ \\
\hline Gender $^{\mathrm{a}}$ & & & $<0.01$ \\
\hline Male $(\%)$ & $7333(47.6)$ & $1763(55.5)$ & \\
\hline Female $(\%)$ & $8084(52.4)$ & $1416(44.5)$ & \\
\hline $\operatorname{Race}(\%)^{\mathrm{a}}$ & & & $<0.01$ \\
\hline Mexican American & $268217.4)$ & $385(12.1)$ & \\
\hline Other Hispanic & $177211.5)$ & $254(8.0)$ & \\
\hline Non-Hispanic White & $6251(40.5)$ & $1391(43.8)$ & \\
\hline Non-Hispanic Black & 3039 19.7) & $811(25.5)$ & \\
\hline Other race & $1673(10.9)$ & $338(10.6)$ & \\
\hline Physical activity $(\%)^{\mathrm{a}}$ & & & $<0.01$ \\
\hline Inactive & $7740(50.2)$ & $1799(56.6)$ & \\
\hline Insufficiently active & $2302(14.9)$ & $455(14.3)$ & \\
\hline Physically active & $5375(34.9)$ & $925(29.1)$ & \\
\hline Waist circumstance $(\mathrm{cm})^{\mathrm{b}}$ & $94.4(20.9)$ & $105.6(20.4)$ & $<0.01$ \\
\hline Body mass index $\left(\mathrm{kg} / \mathrm{m}^{2}\right)^{\mathrm{b}}$ & $27.02(7.77)$ & $30.94(9.1)$ & $<0.01$ \\
\hline Cholesterol $(\mathrm{mmol} / \mathrm{L})^{\mathrm{b}}$ & $4.86(1.40)$ & $5.02(1.47)$ & 0.811 \\
\hline Triglyceride $(\mathrm{mmol} / \mathrm{L})^{\mathrm{b}}$ & $1.25(1.12)$ & $1.67(1.40)$ & $<0.01$ \\
\hline $\mathrm{eGFR}\left(\mathrm{mL} / \mathrm{min} / 1.73 \mathrm{~m}^{2}\right)^{\mathrm{b}}$ & $93.42(29.71)$ & $79.21(32.40)$ & $<0.01$ \\
\hline Poverty income ratio $<1(\%)^{\mathrm{a}}$ & $3445(24.4)$ & $662(22.8)$ & 0.064 \\
\hline Serum uric acid $(\mu \mathrm{mol} / \mathrm{L})^{\mathrm{b}}$ & $297.4(95.2)$ & $440.2(65.4)$ & $<0.01$ \\
\hline Serum $25(\mathrm{OH}) \mathrm{D}(\mathrm{nmol} / \mathrm{L})^{\mathrm{b}}$ & $60.1(33.45)$ & $58.0(36.3)$ & $<0.01$ \\
\hline Total calcium $(\mathrm{mmol} / \mathrm{L})^{\mathrm{b}}$ & $2.35(0.100)$ & $2.38(0.125)$ & $<0.01$ \\
\hline Phosphorus $(\mathrm{mmol} / \mathrm{L})^{\mathrm{b}}$ & $1.23(0.226)$ & $1.23(0.226)$ & 0.892 \\
\hline Hypertension $(\%)^{\mathrm{a}}$ & $4172(27.1)$ & $1598(50.3)$ & $<0.01$ \\
\hline Diabetes $(\%)^{\mathrm{a}}$ & $1452(9.4)$ & $509(16.0)$ & $<0.01$ \\
\hline Had at least 12 alcohol drinks/year $(\%)^{\mathrm{a}}$ & $9780(72.1)$ & $2058(71.5)$ & 0.53 \\
\hline Smoked at least 100 cigarettes in life $(\%)^{\mathrm{a}}$ & 6267 (42.6) & $1451(46.9)$ & $<0.01$ \\
\hline
\end{tabular}

Data are number of subjects (percentage) or medians (interquartile ranges)

${ }^{\mathrm{a}} \chi^{2}$ test was used to compare the percentage between participants with and without hyperuricemia

${ }^{\text {b}}$ Mann-Whitney $U$ test was used to compare the median values between participants with and without hyperuricemia

\begin{tabular}{lllll}
\hline $\begin{array}{l}\text { Serum 25(OH) } \\
\text { D quartiles }\end{array}$ & Case/Participants & Crude $^{\mathrm{a}}$ & Model 1 $^{\mathrm{a}}$ & Model 2 $^{\mathrm{a}}$ \\
\hline Q4 & $4648 / 18596$ & 1.00 (Ref.) & 1.00 (Ref.) & 1.00 (Ref.) \\
Q3 & $4644 / 18596$ & $0.95(0.82-1.09)$ & $0.97(0.84-1.11)$ & $0.96(0.81-1.14)$ \\
Q2 & $4651 / 18596$ & $1.16(0.98-1.37)$ & $1.23(1.04-1.46)^{*}$ & $1.14(0.94-1.38)$ \\
Q1 & $4653 / 18596$ & $1.33(1.14-1.55)^{* *}$ & $1.49(1.28-1.73)^{* *}$ & $1.46(1.22-1.75)^{* *}$ \\
\hline
\end{tabular}

Serum $25(\mathrm{OH}) D$ quartiles $\mathrm{Q} 1(25(\mathrm{OH}) \mathrm{D} \leq 43.20 \mathrm{nmol} / \mathrm{L}), \mathrm{Q} 2(43.20<25(\mathrm{OH}) \mathrm{D} \leq 59.70 \mathrm{nmol} / \mathrm{L}), \mathrm{Q} 3$ $(59.70<25(\mathrm{OH}) \mathrm{D} \leq 77.10 \mathrm{nmol} / \mathrm{L}), \mathrm{Q} 4(25(\mathrm{OH}) \mathrm{D}>77.10 \mathrm{nmol} / \mathrm{L})$, Model 1 adjusted for age and sex, Model 2 adjusted for age, sex and race, $B M I$ waist circumstance, poverty income ratio, physical activity, drinking status, smoking, hypertension, diabetes, total cholesterol, triglyceride, $e G F R$ calcium, phosphorus

${ }^{a}$ Calculated using binary logistic regression

$* P<0.05, * * P<0.01$ 
Fig. 2 Examination of the doseresponse relationship between serum 25(OH)D (nmol/L) and the risk of hyperuricemia by restricted cubic splines model. The restricted cubic splines model adjusted for age, gender, race, BMI: waist circumference, PIR: physical activity, drinking status, smoking status, hypertension, diabetes, total cholesterol, triglyceride, eGFR: serum calcium and phosphorus

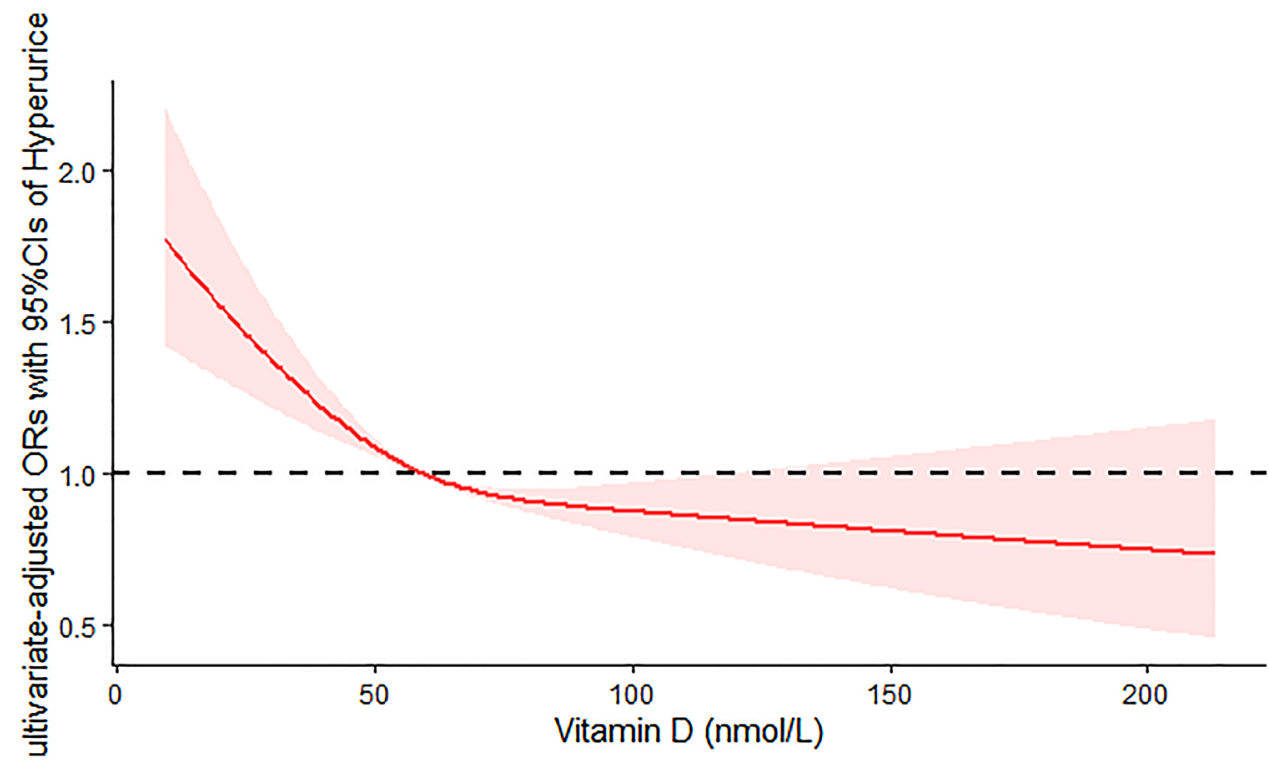

Table 4 Weighted odds ratios (95\% confidence intervals) for hyperuricemia of participants without chronic kidney disease and obesity across quartiles of serum 25(OH)D level, NHANES 2007-2014 $(N=11,006)$

\begin{tabular}{lllll}
\hline Serum 25(OH)D quartiles & Case/Participants & Crude $^{\mathrm{a}}$ & Model 1 $^{\mathrm{a}}$ & Model 2 $^{\mathrm{a}}$ \\
\hline Q4 & $2750 / 11006$ & 1.00 (Ref.) & 1.00 (Ref.) & $1.00($ Ref.) \\
Q3 & $2750 / 11006$ & $1.06(0.87-1.30)$ & $0.96(0.79-1.18)$ & $1.00(0.77-1.30)$ \\
Q2 & $2746 / 11006$ & $1.14(0.90-1.45)$ & $1.05(0.82-1.34)$ & $1.08(0.78-1.48)$ \\
Q1 & $2760 / 11006$ & $1.27(1.01-1.60)^{*}$ & $1.23(0.97-1.56)$ & $1.43(1.06-1.93)^{*}$ \\
\hline
\end{tabular}

Serum $25(\mathrm{OH})$ D quartiles Q1 $(25(\mathrm{OH}) \mathrm{D} \leq 45.50 \mathrm{nmol} / \mathrm{L})$, Q2 $(45.50<25(\mathrm{OH}) \mathrm{D} \leq 61.80 \mathrm{nmol} / \mathrm{L}), \mathrm{Q} 3(61.80<25(\mathrm{OH}) \mathrm{D} \leq 78.90 \mathrm{nmol} / \mathrm{L}), \mathrm{Q} 4$ $(25(\mathrm{OH}) \mathrm{D}>78.90 \mathrm{nmol} / \mathrm{L})$, Model 1 adjusted for age and sex, Model 2 adjusted for age, sex and race, BMI waist circumstance, poverty income ratio, physical activity, drinking status, smoking, hypertension, diabetes, total cholesterol, triglyceride, $e G F R$ serum calcium and phosphorus

${ }^{\mathrm{a}}$ Calculated using binary logistic regression

$* P<0.05, * * P<0.01$

Table 5 The weighted odds ratios (95\% confidence intervals) of hyperuricemia across quartiles of serum 25(OH)D level, stratified analysis by gender, NHANES 2007-2014 $(N=18,596)$

\begin{tabular}{|c|c|c|c|c|c|c|}
\hline \multirow{2}{*}{$\begin{array}{l}25(\mathrm{OH}) \mathrm{D} \\
\text { quartiles }\end{array}$} & \multicolumn{3}{|l|}{ Men } & \multicolumn{3}{|l|}{ Women } \\
\hline & Crude $^{\mathrm{a}}$ & Model $1^{\mathrm{a}}$ & Model $2^{\mathrm{a}}$ & Crude $^{a}$ & Model $1^{\mathrm{a}}$ & Model $2^{\mathrm{a}}$ \\
\hline Q4 & 1.00 (Ref.) & 1.00 (Ref.) & 1.00 (Ref.) & 1.00 (Ref.) & 1.00 (Ref.) & 1.00 (Ref.) \\
\hline Q3 & $0.91(0.76-1.10)$ & $0.91(0.76-1.10)$ & $0.92(0.72-1.16)$ & $0.89(0.71-1.11)$ & $1.09(0.88-1.34)$ & $1.07(0.82-1.39)$ \\
\hline Q2 & $1.15(0.93-1.41)$ & $1.15(0.93-1.42)$ & $1.07(0.82-1.41)$ & $1.03(0.83-1.29)$ & $1.37(1.09-1.72) * *$ & $1.23(0.94-1.62)$ \\
\hline Q1 & $1.28(1.04-1.58) *$ & $1.28(1.04-1.58) *$ & $1.30(1.03-1.65) *$ & $1.34(1.06-1.70) *$ & $1.79(1.43-2.25) * *$ & $1.55(1.13-2.12) * *$ \\
\hline
\end{tabular}

Serum 25(OH)D quartiles Q1 $(25(\mathrm{OH}) \mathrm{D} \leq 43.20 \mathrm{nmol} / \mathrm{L})$, Q2 $(43.20<25(\mathrm{OH}) \mathrm{D} \leq 59.70 \mathrm{nmol} / \mathrm{L}), \mathrm{Q} 3(59.70<25(\mathrm{OH}) \mathrm{D} \leq 77.10 \mathrm{nmol} / \mathrm{L}), \mathrm{Q} 4$ $(25(\mathrm{OH}) \mathrm{D}>77.10 \mathrm{nmol} / \mathrm{L})$, Model 1 adjusted for age, Model 2 adjusted for age, race, BMI waist circumstance, poverty income ratio, physical activity, drinking status, smoking, hypertension, diabetes, total cholesterol, triglyceride, $e G F R$ serum calcium and phosphorus

${ }^{\mathrm{a}}$ Calculated using binary logistic regression

$* P<0.05, * * P<0.01$

due to volumetric dilution into greater volume of serum, fat [50] and less sunlight exposure [51]. Obesity-related adipose tissue inflammation and resulting dysfunction might be the central mechanism for the development of insulin resistance and metabolic diseases, both of which are associated with hypovitaminosis $\mathrm{D}$ and hyperuricemia [52, 53]. In addition, dysfunctional adipose tissue shows a reduced catecholamine-induced release of vitamin D [54]. 
Table 6 Weighted odds ratios (95\% confidence intervals) for hyperuricemia of participants who were diagnosed with metabolic syndrome, NHANES 2007-2014 $(N=6022)$

\begin{tabular}{|c|c|c|c|c|}
\hline $\begin{array}{l}\text { Serum } 25(\mathrm{OH}) \mathrm{D} \\
\text { quartiles }\end{array}$ & Case/Participants & Crude $^{\mathrm{a}}$ & Model $1^{\mathrm{a}}$ & Model $2^{\mathrm{a}}$ \\
\hline Q4 & $1499 / 6022$ & 1.00 (Ref.) & 1.00 (Ref.) & 1.00 (Ref.) \\
\hline Q3 & $1501 / 6022$ & $0.84(0.69-1.02)$ & $0.86(0.71-1.04)$ & $1.06(0.86-1.31)$ \\
\hline Q2 & $1516 / 6022$ & $0.95(0.78-1.16)$ & $0.99(0.82-1.21)$ & $1.16(0.94-1.44)$ \\
\hline Q1 & $1506 / 6022$ & $1.07(0.86-1.32)$ & $1.12(0.91-1.39)$ & $1.49(1.16-1.91) * *$ \\
\hline \multicolumn{5}{|c|}{$\begin{array}{l}\text { Serum } 25(\mathrm{OH}) \mathrm{D} \text { quartiles } \mathrm{Q} 1(25(\mathrm{OH}) \mathrm{D} \leq 43.20 \mathrm{nmol} / \mathrm{L}), \mathrm{Q} 2(43.20<25(\mathrm{OH}) \mathrm{D} \leq 59.70 \mathrm{nmol} / \mathrm{L}), \mathrm{Q} 3 \\
(59.70<25(\mathrm{OH}) \mathrm{D} \leq 77.10 \mathrm{nmol} / \mathrm{L}), \mathrm{Q} 4(25(\mathrm{OH}) \mathrm{D}>77.10 \mathrm{nmol} / \mathrm{L}) \text {, Model } 1 \text { adjusted for age and sex, } \\
\text { Model } 2 \text { adjusted for age, sex and race, BMI, waist circumstance, poverty income ratio, physical activity, } \\
\text { drinking status, smoking, hypertension, diabetes, total cholesterol, triglyceride, } e G F R \text { serum calcium and } \\
\text { phosphorus }\end{array}$} \\
\hline \multicolumn{5}{|c|}{${ }^{a}$ Calculated using binary logistic regression } \\
\hline
\end{tabular}

Our results were consistent with some previous studies [24, 25, 55]. A study conducted in 2013 found that Vitamin $\mathrm{D}$ insufficiency was significantly associated with elevated uric acid among postmenopausal Chinese Han women but not premenopausal women [24]. Another study conducted by Kamil F. Faridi [55], which involved 4591 adults, was designed to investigate the association between Vitamin D and other non-lipid biomarkers found that adults with deficient $25(\mathrm{OH}) \mathrm{D}$ had increased ORs of elevated SUA compared to those with optimal $25(\mathrm{OH}) \mathrm{D}$ level. However, there is also some controversial evidence $[26,27,56]$. Two crosssectional studies conducted by Savas Sipahi [26] and Markus J. Seibel [27], respectively, found that SUA was positively associated with $25(\mathrm{OH}) \mathrm{D}$ after adjusting for several potential confounders. Possible explanations of the differences in the above research results included the following: (1) the inclusion and exclusion criteria were diferent among previous research, so there were diferences in the participants, such as Savas Sipahi's study only involved chronic kidney disease (CKD) patients and Markus J.Seibel's only involved male participants aged 70 year old and over, which were not representative in normal population; (2) there were differences in the research methods, statistical analysis and adjusted confounding factors, which may also explain the difference.

Our study has some advantages: first, we used a large national representative sample among the general US population which increased the statistical strength to provide a reliable result and we analyzed this association with different statistical methods and fully adjusted the potential confounding factors. We used quartiles of serum vitamin D to explore the relationship between vitamin D and SUA, and we used restricted cubic splines to describe the dose-response relationship between vitamin D and hyperuricemia for the first time. Furthermore, elevated uric acid and secondary hyperparathyroidism are common among CKD patients, so we performed sensitivity analysis by excluding CKD participants to minimize the effect of hyperparathyroidism and renal dysfunction on SUA. Vitamin D, as a fat-soluble vitamin, is lower in the obese people while SUA is higher compared with normal people [50]. To minimize the influence of obesity and fat on the association, we adjusted the BMI, waist circumference, total cholesterol and triglyceride and performed a sensitivity analysis by excluding obesity participants $\left(\mathrm{BMI} \geq 30 \mathrm{~kg} / \mathrm{m}^{2}\right)$. Although data on the time of sun exposure were not available, we used serum $25(\mathrm{OH}) \mathrm{D}$, which reflected cumulative endogenous synthesis and exogenous supplement, as a direct measure of Vitamin D status to minimize the influence of sun exposure.

However, our study has some limitations. Primarily, as a crosssectional study, it was difficult to determine causality between Vitamin D and SUA. In future, large-scale prospective studies might be required to confirm the causal relationship. Furthermore, due to the limited data, we only analyzed the relationship between SUA and 25(OH)D but did not further analyze the effects of $1,25(\mathrm{OH}) \mathrm{D}$ on SUA. In addition, though we performed sensitivity analysis to minimize the influence of PTH, due to lack of PTH data, we could not determine whether the association of $25(\mathrm{OH}) \mathrm{D}$ with SUA was partly mediated by PTH and how it mediated. Finally, due to limited data, the dietary regimen information of participants was not involved. Previous studies had proved that different dietary regimens such as ketogenic diets, higher meat, seafood, alcohol and sugar sweetened beverage intake are associated with increased risk of hyperuricemia, while increased Vitamin $\mathrm{C}$ intake is associated with decreased hyperuricemia risk [57-60].

It is generally agreed that gout patients should initiate urate-lowering therapy to achieve a specific SUA target, while for asymptomatic hyperuricemia patients, it is not approved in most countries to start uric acid-lowering therapy because of the potential serious adverse effects [61-63]. From this study, for people with unexplained hyperuricemia, it might be necessary to screen serum Vitamin D concentration. Although Vitamin D supplementation has little adverse effects, further studies are needed to explore whether 
patients with hyperuricemia can benefit from vitamin D supplementation.

\section{Conclusions}

Our study suggests that serum 25(OH)D might be inversely associated with hyperuricemia in general U.S. adults. We hope that it can provide some information for the screening of Vitamin D deficiency and treatment of hyperuricemia. The association we investigated in this study is biologically plausible, and further large-scale prospective studies are required to confirm the causal relationship between SUA and $25(\mathrm{OH}) \mathrm{D}$.

Acknowledgements Thanks for Dr. Jiayi Yi for his generous guidance in statistics and $\mathrm{R}$ programming. We acknowledge the support from the National Natural Science Foundation of China (Grand No. 82071841 ) and National Natural Science Foundation of China (Grand No. 81901667) and CAMS Innovation Fund for Medical Sciences (No. 2019XK320013). We acknowledge the staff at the National Center for Health Statistics at the CDC, who design, collect, and administer the NHANES data and release the data for public use. We are grateful to all study participants for their cooperation.

Author contributions All authors contributed to the study conception and design. Material preparation, data collection and analysis were performed by $\mathrm{YH}, \mathrm{YZ}$ and $\mathrm{KH}$. The first draft of the manuscript was written by $\mathrm{YH}, \mathrm{YZ}$ and $\mathrm{KH}$ and all authors commented on previous versions of the manuscript. All authors read and approved the final manuscript.

Funding This work was supported by grant from the National Natural Science Foundation of China (Grant No. 82071841) and National Natural Science Foundation of China (Grant No. 81901667) and CAMS Innovation Fund for Medical Sciences (CIFMS 2020-I2M-2-009), the Clinical and translational medical research fund of Chinese Academy of Medical Sciences (No.2019XK320013).

Data availability statement The datasets supporting the conclusions of this article are available in the public repository as described below. The authors do not own the data. National Health and Nutrition Examination Survey data are available from the National Center for Health Statistics (http://www.cdc.gov/nchs/nhanes/nhanes_questionnaires.htm)

\section{Declarations}

Conflict of interest The authors have no conflicts of interest to declare that are relevant to the content of this article.

Ethical approval The study was conducted ethically in accordance with the 1964 Declaration of Helsinki. The National Center for Health Statistics' Research Ethics Review Board reviewed and approved all data collection protocols

Informed consent Written informed consent was obtained from all participants prior to completing the NHANES, and all data were deidentified by the NCHS before being made publicly available.
Consent to participate Informed consent was obtained from all individual participants included in the study.

Consent to publish Patients signed informed consent regarding publishing their data and photographs.

Open Access This article is licensed under a Creative Commons Attribution 4.0 International License, which permits use, sharing, adaptation, distribution and reproduction in any medium or format, as long as you give appropriate credit to the original author(s) and the source, provide a link to the Creative Commons licence, and indicate if changes were made. The images or other third party material in this article are included in the article's Creative Commons licence, unless indicated otherwise in a credit line to the material. If material is not included in the article's Creative Commons licence and your intended use is not permitted by statutory regulation or exceeds the permitted use, you will need to obtain permission directly from the copyright holder. To view a copy of this licence, visit http://creativecommons.org/licenses/by/4.0/.

\section{References}

1. Ganji V, Zhang X, Tangpricha V (2012) Serum 25-hydroxyvitamin D concentrations and prevalence estimates of hypovitaminosis D in the U.S. population based on assay-adjusted data. J Nutr 142(3):498-507. https://doi.org/10.3945/jn.111.151977

2. Herrick KA, Storandt RJ, Afful J, Pfeiffer CM, Schleicher RL, Gahche JJ et al (2019) Vitamin D status in the United States, 2011-2014. Am J Clin Nutr 110(1):150-157. https://doi.org/10. 1093/ajcn/nqz037

3. Li YC, Kong J, Wei M, Chen Z-F, Liu SQ, Cao L-P (2002) 1,25 -Dihydroxyvitamin $\mathrm{D} 3$ is a negative endocrine regulator of the renin-angiotensin system. J Clin Investig 110(2):229-238. https://doi.org/10.1172/jci200215219

4. Szymczak-Pajor I, Sliwinska A (2019) Analysis of association between vitamin $\mathrm{D}$ deficiency and insulin resistance. Nutrients. https://doi.org/10.3390/nu11040794

5. Samuel S, Sitrin MD (2008) Vitamin D's role in cell proliferation and differentiation. Nutr Rev 66(10 Suppl 2):S116-S124. https://doi.org/10.1111/j.1753-4887.2008.00094.x

6. Forman JP, Giovannucci E, Holmes MD, Bischoff-Ferrari HA, Tworoger SS, Willett WC et al (2007) Plasma 25-hydroxyvitamin D levels and risk of incident hypertension. Hypertension 49(5):1063-1069. https://doi.org/10.1161/HYPERTENSI ONAHA.107.087288

7. Del Pinto R, Wright JT, Monaco A, Pietropaoli D, Ferri C (2020) Vitamin D and blood pressure control among hypertensive adults: results from NHANES 2001-2014. J Hypertens 38(1):150-158. https://doi.org/10.1097/hjh.0000000000002231

8. Wang L, Song Y, Manson JE, Pilz S, März W, Michaëlsson $\mathrm{K}$ et al (2012) Circulating 25-hydroxy-vitamin D and risk of cardiovascular disease: a meta-analysis of prospective studies. Circ Cardiovasc Qual Outcomes 5(6):819-829. https://doi.org/ 10.1161/circoutcomes.112.967604

9. Yilmaz H, Kaya M, Sahin M, Delibasi T (2012) Is vitamin D status a predictor glycaemic regulation and cardiac complication in type 2 diabetes mellitus patients? Diabetes Metab Syndr 6(1):28-31. https://doi.org/10.1016/j.dsx.2012.05.007

10. Tian LQ, Shi WQ, Zhou Y, Zhang YW, Zhang ML (2019) The association of serum Vitamin D deficiency and metabolic risk factors in Chinese adults with prediabetes: a cross-sectional study. J Nutr Sci Vitaminol 65(3):211-218. https://doi.org/10. 3177/jnsv.65.211 
11. Murdaca G, Tonacci A, Negrini S, Greco M, Borro M, Puppo F et al (2019) Emerging role of vitamin D in autoimmune diseases: an update on evidence and therapeutic implications. Autoimmun Rev 18(9):102350. https://doi.org/10.1016/j.autrev. 2019.102350

12. McMullan CJ, Borgi L, Curhan GC, Fisher N, Forman JP (2017) The effect of vitamin D on renin-angiotensin system activation and blood pressure: a randomized control trial. J Hypertens 35(4):822-829. https://doi.org/10.1097/HJH.0000000000001220

13. Pittas AG, Jorde R, Kawahara T, Dawson-Hughes B (2020) Vitamin D supplementation for prevention of type 2 diabetes mellitus: to D or not to D? J Clin Endocrinol Metab. https://doi. org/10.1210/clinem/dgaa594

14. Yamamoto E, Jorgensen TN (2019) Immunological effects of vitamin $\mathrm{D}$ and their relations to autoimmunity. J Autoimmun 100:7-16. https://doi.org/10.1016/j.jaut.2019.03.002

15. Wang TJ (2016) Vitamin D and cardiovascular disease. Annu Rev Med 67:261-272. https://doi.org/10.1146/annur ev-med-051214-025146

16. Mandal AK, Mount DB (2015) The molecular physiology of uric acid homeostasis. Annu Rev Physiol 77:323-345. https:// doi.org/10.1146/annurev-physiol-021113-170343

17. Zhu Y, Pandya BJ, Choi HK (2011) Prevalence of gout and hyperuricemia in the US general population: the National Health and Nutrition Examination Survey 2007-2008. Arthritis Rheum 63(10):3136-3141. https://doi.org/10.1002/art.30520

18. Li C, Hsieh MC, Chang SJ (2013) Metabolic syndrome, diabetes, and hyperuricemia. Curr Opin Rheumatol 25(2):210-216. https:// doi.org/10.1097/BOR.0b013e32835d951e

19. Biradar MI, Chiang KM, Yang HC, Huang YT, Pan WH (2019) The causal role of elevated uric acid and waist circumference on the risk of metabolic syndrome components. Int J Obes. https:// doi.org/10.1038/s41366-019-0487-9

20. Paik JM, Kim SC, Feskanich D, Choi HK, Solomon DH, Curhan GC (2017) Gout and risk of fracture in women: a prospective cohort study. Arthritis Rheumatol 69(2):422-428. https://doi.org/ 10.1002/art.39852

21. De Becker B, Borghi C, Burnier M, van de Borne P (2019) Uric acid and hypertension: a focused review and practical recommendations. J Hypertens 37(5):878-883. https://doi.org/10.1097/HJH. 0000000000001980

22. Fang J, Alderman MH (2000) Serum uric acid and cardiovascular mortality the NHANES I epidemiologic follow-up study, 1971-1992. National Health and Nutrition Examination Survey. JAMA 283(18):2404-2410. https://doi.org/10.1001/jama.283.18. 2404

23. Konta T, Ichikawa K, Kawasaki R, Fujimoto S, Iseki K, Moriyama $T$ et al (2020) Association between serum uric acid levels and mortality: a nationwide community-based cohort study. Sci Rep 10(1):6066. https://doi.org/10.1038/s41598-020-63134-0

24. Peng H, Li H, Li C, Chao X, Zhang Q, Zhang Y (2013) Association between vitamin $\mathrm{D}$ insufficiency and elevated serum uric acid among middle-aged and elderly Chinese Han women. PLoS ONE 8(4):e61159. https://doi.org/10.1371/journal.pone.0061159

25. Nakhl S, Sleilaty G, El Samad S, Saliba Y, Chahine R, Fares N (2019) Association between vitamin D deficiency and lipid and non-lipid markers of cardiovascular diseases in the middle east region. Eur J Clin Nutr 73(6):850-858. https://doi.org/10.1038/ s41430-018-0280-1

26. Sipahi S, Acikgoz SB, Genc AB, Yildirim M, Solak Y, Tamer A (2017) The association of vitamin D status and vitamin D replacement therapy with glycemic control, serum uric acid levels, and microalbuminuria in patients with type 2 diabetes and chronic kidney disease. Med Princ Pract 26(2):146-151. https://doi.org/ $10.1159 / 000454952$
27. Nabipour I, Sambrook PN, Blyth FM, Janu MR, Waite LM, Naganathan V et al (2011) Serum uric acid is associated with bone health in older men: a cross-sectional population-based study. $\mathrm{J}$ Bone Miner Res 26(5):955-964. https://doi.org/10.1002/jbmr.286

28. Zou Q, Wang H, Su C, Du W, Ouyang Y, Jia X et al (2021) Longitudinal association between physical activity and blood pressure, risk of hypertension among Chinese adults: China Health and Nutrition Survey 1991-2015. Eur J Clin Nutr 75(2):274-282. https://doi.org/10.1038/s41430-020-0653-0

29. World Medical Association Declaration of Helsinki. Ethical Principles for Medical Research. Involving Human Subjects. https://www.wma.net/wp-content/uploads/2016/11/DoH-Oct20 13-JAMA.pdf. Accessed 25 Oct 2020

30. Johnson RJ, Kang DH, Feig D, Kivlighn S, Kanellis J, Watanabe $\mathrm{S}$ et al (2003) Is there a pathogenetic role for uric acid in hypertension and cardiovascular and renal disease? Hypertension 41(6):1183-1190. https://doi.org/10.1161/01.HYP.0000069700. $62727 . \mathrm{C} 5$

31. Al-khalidi B, Kimball SM, Rotondi MA, Ardern CI (2017) Standardized serum 25-hydroxyvitamin D concentrations are inversely associated with cardiometabolic disease in U.S. adults: a crosssectional analysis of NHANES, 2001-2010. Nutr J. https://doi. org/10.1186/s12937-017-0237-6

32. Schleicher RL, Sternberg MR, Lacher DA, Sempos CT, Looker AC, Durazo-Arvizu RA et al (2016) The vitamin D status of the US population from 1988 to 2010 using standardized serum concentrations of 25-hydroxyvitamin D shows recent modest increases. Am J Clin Nutr 104(2):454-461. https://doi.org/10. 3945/ajcn.115.127985

33. Zhao F, Liu Q, Li Y, Feng X, Chang H, Lyu J (2020) Association between alcohol consumption and hypertension in Chinese adults: findings from the CHNS. Alcohol (Fayetteville, NY) 83:83-88. https://doi.org/10.1016/j.alcohol.2019.09.004

34. Feig DI, Kang DH, Johnson RJ (2008) Uric acid and cardiovascular risk. N Engl J Med 359(17):1811-1821. https://doi.org/ 10.1056/NEJMra0800885

35. Feig DI (2011) Uric acid and hypertension. Semin Nephrol 31(5):441-446. https://doi.org/10.1016/j.semnephrol.2011.08. 008

36. Levey AS, Coresh J, Greene T, Stevens LA, Zhang YL, Hendriksen $S$ et al (2006) Using standardized serum creatinine values in the modification of diet in renal disease study equation for estimating glomerular filtration rate. Ann Intern Med 145(4):247-254. https://doi.org/10.7326/0003-4819-145-4200608150-00004

37. Chen W, Roncal-Jimenez C, Lanaspa M, Gerard S, Chonchol M, Johnson RJ et al (2014) Uric acid suppresses 1 alpha hydroxylase in vitro and in vivo. Metabolism 63(1):150-160. https://doi.org/ 10.1016/j.metabol.2013.09.018

38. Mazzali M, Hughes J, Kim YG, Jefferson JA, Kang DH, Gordon KL et al (2001) Elevated uric acid increases blood pressure in the rat by a novel crystal-independent mechanism. Hypertension 38(5):1101-1106. https://doi.org/10.1161/hy1101.092839

39. Alberti KG, Eckel RH, Grundy SM, Zimmet PZ, Cleeman JI, Donato KA et al (2009) Harmonizing the metabolic syndrome: a joint interim statement of the International Diabetes Federation Task Force on Epidemiology and Prevention; National Heart, Lung, and Blood Institute; American Heart Association; World Heart Federation; International Atherosclerosis Society; and International Association for the Study of Obesity. Circulation 120(16):1640-1645. https://doi.org/10.1161/CIRCULATIO NAHA.109.192644

40. Park J, Ryu SY, Han MA, Choi SW (2016) The association of Vitamin D with estimated glomerular filtration rate and albuminuria: 5th Korean National Health and Nutritional Examination 
Survey 2011-2012. J Ren Nutr 26(6):360-366. https://doi.org/10. 1053/j.jrn.2016.07.003

41. Hsu S, Zelnick LR, Lin YS, Best CM, Kestenbaum B, Thummel KE et al (2021) Differences in 25-hydroxyvitamin D clearance by eGFR and race: a pharmacokinetic study. J Am Soc Nephrol 32(1):188-198. https://doi.org/10.1681/asn.2020050625

42. Lips P (2001) Vitamin D deficiency and secondary hyperparathyroidism in the elderly: consequences for bone loss and fractures and therapeutic implications. Endocr Rev 22(4):477-501. https:// doi.org/10.1210/edrv.22.4.0437

43. Aloia J, Bojadzievski T, Yusupov E, Shahzad G, Pollack S, Mikhail M et al (2010) The relative influence of calcium intake and vitamin $\mathrm{D}$ status on serum parathyroid hormone and bone turnover biomarkers in a double-blind, placebo-controlled parallel group, longitudinal factorial design. J Clin Endocrinol Metab 95(7):3216-3224. https://doi.org/10.1210/jc.2009-1294

44. Jorde R, Sundsfjord J, Haug E, Bonaa KH (2000) Relation between low calcium intake, parathyroid hormone, and blood pressure. Hypertension 35(5):1154-1159. https://doi.org/10.1161/ 01.hyp.35.5.1154

45. Hui JY, Choi JW, Mount DB, Zhu Y, Zhang Y, Choi HK (2012) The independent association between parathyroid hormone levels and hyperuricemia: a national population study. Arthritis Res Ther 14(2):R56. https://doi.org/10.1186/ar3769

46. Chin KY, Nirwana SI, Ngah WZ (2015) Significant association between parathyroid hormone and uric acid level in men. Clin Interv Aging 10:1377-1380. https://doi.org/10.2147/CIA.S90233

47. Lu L, Yu Z, Pan A, Hu FB, Franco OH, Li H et al (2009) Plasma 25-hydroxyvitamin D concentration and metabolic syndrome among middle-aged and elderly Chinese individuals. Diabetes Care 32(7):1278-1283. https://doi.org/10.2337/dc09-0209

48. Kayaniyil S, Vieth R, Retnakaran R, Knight JA, Qi Y, Gerstein HC et al (2010) Association of vitamin D with insulin resistance and beta-cell dysfunction in subjects at risk for type 2 diabetes. Diabetes Care 33(6):1379-1381. https://doi.org/10.2337/dc09-2321

49. Asemi Z, Samimi M, Tabassi Z, Shakeri H, Esmaillzadeh A (2013) Vitamin D supplementation affects serum high-sensitivity C-reactive protein, insulin resistance, and biomarkers of oxidative stress in pregnant women. J Nutr 143(9):1432-1438. https://doi. org/10.3945/jn.113.177550

50. Walsh JS, Bowles S, Evans AL (2017) Vitamin D in obesity. Curr Opin Endocrinol Diabetes Obes 24(6):389-394. https://doi.org/ 10.1097/MED.0000000000000371

51. Kull M, Kallikorm R, Lember M (2009) Body mass index determines sunbathing habits: implications on vitamin $\mathrm{D}$ levels. Intern Med J 39(4):256-258. https://doi.org/10.1111/j.1445-5994.2009. 01900.x

52. Oikonomou EK, Antoniades C (2019) The role of adipose tissue in cardiovascular health and disease. Nat Rev Cardiol 16(2):83-99. https://doi.org/10.1038/s41569-018-0097-6

53. Longo M, Zatterale F, Naderi J, Parrillo L, Formisano P, Raciti GA et al (2019) Adipose tissue dysfunction as determinant of obesity-associated metabolic complications. Int J Mol Sci. https:// doi.org/10.3390/ijms20092358

54. Di Nisio A, De Toni L, Sabovic I, Rocca MS, De Filippis V, Opocher G et al (2017) Impaired release of vitamin D in dysfunctional adipose tissue: new cues on vitamin $\mathrm{D}$ supplementation in obesity. J Clin Endocrinol Metab 102(7):2564-2574. https://doi. org/10.1210/jc.2016-3591

55. Faridi KF, Lupton JR, Martin SS, Banach M, Quispe R, Kulkarni $\mathrm{K}$ et al (2017) Vitamin D deficiency and non-lipid biomarkers of cardiovascular risk. Arch Med Sci 13(4):732-737. https://doi.org/ 10.5114/aoms.2017.68237

56. Karimi F, Dabbaghmanesh MH, Omrani GR (2019) Association between serum uric acid and bone health in adolescents. Osteoporos Int 30(10):2057-2064. https://doi.org/10.1007/ s00198-019-05072-w

57. Lee SJ, Terkeltaub RA, Kavanaugh A (2006) Recent developments in diet and gout. Curr Opin Rheumatol 18(2):193-198. https://doi. org/10.1097/01.bor.0000209434.82096.1f

58. Schwartz RM, Boyes S, Aynsley-Green A (1989) Metabolic effects of three ketogenic diets in the treatment of severe epilepsy. Dev Med Child Neurol 31(2):152-160. https://doi.org/10.1111/j. 1469-8749.1989.tb03973.x

59. Bae J, Shin DH, Chun BY, Choi BY, Kim MK, Shin MH et al (2014) The effect of vitamin C intake on the risk of hyperuricemia and serum uric acid level in Korean Multi-Rural Communities Cohort. Joint Bone Spine 81(6):513-519. https://doi.org/10. 1016/j.jbspin.2014.05.007

60. Ebrahimpour-Koujan S, Saneei P, Larijani B, Esmaillzadeh A (2020) Consumption of sugar sweetened beverages and dietary fructose in relation to risk of gout and hyperuricemia: a systematic review and meta-analysis. Crit Rev Food Sci Nutr 60(1):1-10. https://doi.org/10.1080/10408398.2018.1503155

61. Dalbeth N, Choi HK, Joosten LAB, Khanna PP, Matsuo H, PerezRuiz F et al (2019) Gout. Nat Rev Dis Prim 5(1):69. https://doi. org/10.1038/s41572-019-0115-y

62. Khanna D, Fitzgerald JD, Khanna PP, Bae S, Singh MK, Neogi $T$ et al (2012) American College of Rheumatology guidelines for management of gout. Part 1: systematic nonpharmacologic and pharmacologic therapeutic approaches to hyperuricemia. Arthritis Care Res (Hoboken) 64(10):1431-1446. https://doi.org/10.1002/ acr. 21772

63. Richette P, Doherty M, Pascual E, Barskova V, Becce F, Castaneda-Sanabria J et al (2017) 2016 updated EULAR evidence-based recommendations for the management of gout. Ann Rheum Dis 76(1):29-42. https://doi.org/10.1136/annrh eumdis-2016-209707

Publisher's Note Springer Nature remains neutral with regard to jurisdictional claims in published maps and institutional affiliations. 